\title{
Extracytoplasmic proteins of Mycobacterium tuberculosis - mature secreted proteins often start with aspartic acid and proline
}

\author{
Harald G. Wiker, ${ }^{1}$ Mike A. Wilson ${ }^{2}$ and Gary K. Schoolnik ${ }^{2}$ \\ Author for correspondence: Harald G. Wiker. Tel: +47220422 00. Fax: +4722042686. \\ e-mail: harald.g.wiker@folkehelsa.no
}

1 Department of Environmental Medicine, National Institute of Public Health, PO Box 4404 Torshov, N-0403 Oslo, Norway

2 Beckman Center, Department of Microbiology and Immunology, Stanford University Medical Center, CA 94305, USA

\begin{abstract}
A surrogate expression system, based on fusions to the phoA bacterial reporter gene, was used to identify Mycobacterium tuberculosis genes that encode exported proteins and the promoter regions required for their expression in the heterologous host Mycobacterium smegmatis. To assess these results in the context of the complete $M$. tuberculosis genome sequence, the corresponding genes were identified and computational algorithms were employed to identify signal peptide (SP), transmembrane domain and membrane lipoprotein attachment motifs. This information was used to predict the subset of $M$. tuberculosis genes that encode exported proteins. Of the 34 genes identified by the phoA method, 22 were classified to encode potential soluble secreted proteins. Among these, 14 genes may encode novel secreted proteins. Six of the remaining 12 genes were predicted to encode membrane lipoproteins and an additional six to encode integral membrane proteins. Published observations of proteins proven to be secreted into M. tuberculosis culture filtrates were reviewed to further characterize the mycobacterial SP motif. It was concluded that mycobacterial SPs are comparable in size to Gram-positive SPs, but certain features are different. In particular, arginine was the predominant $\mathbf{N}$-terminally positively charged amino acid in contrast to lysine in the Gram-positives. The hydrophobic transmembrane segment of the SP was dominated by alanine, in contrast to leucine. At the C-terminal end of the SPs, the $(-3,-1)$ rule (AXA motif) holds, with alanine as the dominant amino acid in both positions, being most dominant in the (-1) position. A high proportion of mature sequences start with aspartic acid in the $(+1)$ position and proline in the $(+2)$ position - the DP motif. The authors propose that the DP sequence serves as a sorting signal, following translocation and cleavage by signal peptidase I. Alternatively, the DP motif may be part of the recognition site for the signal peptidase.
\end{abstract}

Keywords: Mycobacterium tuberculosis, Mycobacterium smegmatis, alkaline phosphatase A fusions, protein export, signal sequence

\section{INTRODUCTION}

A continuing challenge of the post-genomic era will be to integrate experimental data with the genome sequence. Most published annotation approaches for categorizing predicted ORFs of microbial genomes have been patterned after the functional categories defined for Escherichia coli by Riley (1993). Although this

Abbreviations: $\mathrm{HMM}$, hidden Markov model; NN, neural network; PhoA, alkaline phosphatase $\mathrm{A}$; SP, signal peptide; TM, transmembrane. approach has been exceptionally useful for initial gene groupings, its categorical approach limits each gene to a single assignment and fails to account for the complexities that are known to contribute to the biological properties of a gene. One proposal for improving this system is to add categorical depth to reflect each ORF's membership with regard to multiple properties, including subcellular localization, regulation, structural features, motifs and enzymic activities (Riley, 1998). The subcellular location has important biological significance and implications for vaccine and drug 
development strategies. In particular, proteins secreted across the cytoplasmic membrane are likely to be involved with cell wall biogenesis, mediate virulence or contain prominent antigenic determinants.

For Mycobacterium tuberculosis, the phoA reporter system has been established in a surrogate model and used to identify several exported proteins (Lim et al., 1995). Fundamental to the successful identification of clones that confer positive PhoA activity are two features: (i) in-frame fusion with phoA identifies an ORF that is expressed by the cell; and (ii) enough of the $\mathrm{N}$-terminal features of $M$. tuberculosis secreted proteins must be present to direct export of the chimeric protein across the cytoplasmic membrane.

This study was done to identify M. tuberculosis secreted proteins and to test the validity of computational model predictions. Proteins were evaluated for their potential to be located extracytoplasmically by one of three different criteria: (I) experimentally, by exhibiting PhoA positivity in Mycobacterium smegmatis; (II) computationally, by the presence of either a signal peptide (SP) or a transmembrane (TM) domain or a membrane lipoprotein attachment motif; and (III) by literature review to identify native $M$. tuberculosis proteins secreted into spent culture medium and which therefore are likely to possess authenic signal peptides.

\section{METHODS}

Strains and plasmid construction. M. tuberculosis strain 3609 is a clinical isolate that was provided by the San Francisco Department of Public Health. It was cultured in 7H10 medium (Difco) supplemented with bovine serum albumin and glucose (Jacobs et al., 1991). M. smegmatis, strain $\mathrm{mc}^{2} 155$, was a gift from William Jacobs (Albert Einstein College of Medicine). E. coli strain CC118 ( $p h o A)$, was a gift from Colin Manoil (Genetics, University of Washington). Liquid cultures of $\mathrm{mc}^{2} 155$ and CC118 were grown in Luria-Bertani (LB) broth at $37^{\circ} \mathrm{C}$ with shaking; the medium for $\mathrm{mc}^{2} 155$ was supplemented with $0.05 \%$ Tween 80 (Sigma). Toru Tobe (University of Tokyo, Japan) provided pBS.ATS, a derivative of the pBluescript II KS cloning vector (Strategene) (Sarmientos et al., 1983). Douglas Young (Imperial College School of Medicine, London, UK) provided the shuttle vector pOLYG (Rauzier et al., 1988).

A three-step cloning strategy was used to make the shuttle vector we used for creating the phoA fusions. The pJEM11 (Lim et al., 1995) vector is similar to the vector described here. First, the $51 \mathrm{bp} \mathrm{ClaI-XbaI} \mathrm{fragment} \mathrm{of} \mathrm{pOLYG} \mathrm{was}$ replaced with a $21 \mathrm{bp}$ fragment formed by a pair of complementary oligonucleotides (5'-CTAGTACGTACGCGTTAACTT-3' and 5'-CGAAGTTAACGCGTACGTA-3') that contributed unique SnaBI, MluI and $H p a \mathrm{I}$ sites to the resulting plasmid, pAW99. The second step created pAW100 by inserting the BssHII cassette of pBS.ATS, which contains the Bluescript multicloning cassette flanked by transcriptional terminators, into the MluI site of pAW99. The third step, as described below, created pAW200 by inserting a modified E. coli phoA fragment into the BamHI$\mathrm{XbaI}$ sites of the pAW100 polylinker. We used PCR amplification to modify the E. coli phoA gene in order to remove the promoter and the $\mathrm{N}$-terminal portion of the coding region up to the eighth amino acid of the mature polypeptide. The oligonucleotide primers used for this purpose were 5'-GCCATTAAGTCTAGATGCTAACAGCA-3' and 5'-TGTTCTGGATCCATGGGCTGCTCAGGGCGAT-3'. The resulting $1.4 \mathrm{~kb}$ fragment (designated 'phoA) contains a BamHI site near the N-terminus and an $\mathrm{Xba \textrm {I }}$ site $53 \mathrm{bp}$ downstream from the 'phoA stop codon. Thus, the first three codons of the 'phoA gene were mutated from ENR (corresponding to codons 9-11 of the mature polypeptide) to DPW.

Creation of phoA fusions to $M$. tuberculosis DNA. $M$. tuberculosis genomic DNA was extracted as described by van Soolingen et al. (1991). To generate arbitrary small fragments for cloning, the DNA was partially digested by a mixture of pooled, frequent-cutting restriction enzymes $\left(0 \cdot 01 \mathrm{U} \mathrm{\mu g}^{-1}\right.$ of each enzyme) : AluI, DdeI, HaeIII, HincII, HinfI, MseI, MspI, RsaI, Sau3AI and Sau96I (New England Biolabs) in a standard buffer $\left(10 \mathrm{mM}\right.$ Tris/HCl, pH 7.9, $10 \mathrm{mM} \mathrm{MgCl}_{2}, 50 \mathrm{mM}$ $\mathrm{NaCl}, 1 \mathrm{mM}$ DTT and $100 \mu \mathrm{g} \mathrm{m}^{-1}$ BSA). A digestion of $10 \mathrm{~min}$ at $37^{\circ} \mathrm{C}$ produced a distribution of fragments averaging about $500 \mathrm{bp}$. The DNA was extracted five times in phenol/chloroform $(1: 1, \mathrm{v} / \mathrm{v})$, and the fragment ends were made blunt-ended by treatment with $P f u$ DNA polymerase (Stratagene). The DNA was extracted again in phenol/ chloroform, precipitated in ethanol, washed in $70 \%$ ethanol, dried and dissolved in TE buffer $(10 \mathrm{mM}$ Tris $/ \mathrm{HCl}, \mathrm{pH} 8 \cdot 0$, $1 \mathrm{mM}$ EDTA) to $0.5 \mu \mathrm{g} \mu \mathrm{l}^{-1}$.

Cloning adapters were made from a pair of complementary oligonucleotides (5'-pTCAGCTACTCAG-3' and 5'-pATCCTGAGTAGCTGA-3'). The double-stranded adapters were designed to form one blunt end (which ligates to $M$. tuberculosis fragments) and a 3-base (5'-ATC) protrusion on the opposite end which prevents self-ligation but promotes ligation into a BamHI site that is partially G-filled. The adapter sequence, when translated in one orientation, adds five in-frame codons (Ser-Ala-Thr-Gln-Asp) when fused to the 3 ' end of 'phoA. Translation of the adapter in the opposite orientation produces a stop codon in each of the three reading frames. Adapters were ligated onto the M. tuberculosis DNA fragments using T4 DNA ligase $\left(8 \mathrm{U} \mathrm{ml}^{-1}\right.$, New England Biolabs) in a buffer designed for blunt-end ligations $(50 \mathrm{mM}$ Tris/ $\mathrm{HCl}, \mathrm{pH} 7 \cdot 8,10 \mathrm{mM} \mathrm{MgCl}, 10 \mathrm{mM}$ DTT, $50 \mu \mathrm{M}$ ATP and $\left.25 \mu \mathrm{g} \mathrm{ml}^{-1} \mathrm{BSA}\right)$. After the ligation reaction, unincorporated adapters and small fragments $(<200 \mathrm{bp})$ of $M$. tuberculosis DNA were separated from the larger fragments on a BioGel A-5m resin (Bio-Rad). The larger fragments were precipitated in ethanol and dissolved in $20 \mu \mathrm{l} \mathrm{TE}$ and ligated into the unique BamHI site of pAW200. The resulting plasmid pool was electroporated into E. coli CC118, and the cells cultured on LB agar containing $200 \mu \mathrm{g}$ hygromycin $\mathrm{ml}^{-1}$. Approximately $80 \%$ of the transformed clones had inserts of M. tuberculosis DNA. The colonies of transformed E. coli were scraped from the plates and plasmids were isolated from the pool using a purification kit (Qiagen). The pooled plasmids ( $1 \mu \mathrm{g}$ doses) were transformed into $50 \mu \mathrm{l}$ of $\mathrm{M}$. smegmatis $\mathrm{mc}^{2} 155$, which had been prepared fresh for electroporation as described by Jacobs et al. (1991). Transformants were diluted and plated onto LB agar containing $50 \mu \mathrm{g}$ hygromycin $\mathrm{ml}^{-1}$ and $40 \mu \mathrm{g} 5$-bromo-4-chloro-3-indolyl phosphate (BCIP, Sigma) $\mathrm{ml}^{-1}$. The colonies were grown for $5 \mathrm{~d}$ on plates and kept at $37^{\circ} \mathrm{C}$ in light-proof, humidified chambers. Colonies that developed a blue colour within the $5 \mathrm{~d}$ evaluation period 
Table 1. Exported lipoproteins identified by PhoA fusions

\begin{tabular}{|c|c|c|c|c|c|c|}
\hline Gene no.* & $\begin{array}{l}\text { Total } \\
\text { length } \dagger\end{array}$ & Fusion length $\neq$ & $\begin{array}{c}\text { SP } \\
\text { length } \mathbb{S}\end{array}$ & $\begin{array}{c}\mathrm{TM} \\
\text { domains }\end{array}$ & Signal peptide $\|$ & Alternative designations, comments \\
\hline Rv0432 & 240 & $11,39,44,107$ & 32 & 1 & $\stackrel{+}{\operatorname{MPKPADHRNH}} \stackrel{+}{\mathrm{A} A V S T S V L S A L F L G A G A \mid A L L S A} \downarrow \mid C S S P Q$ & $\begin{array}{l}\text { SodC, superoxide dismutase } \\
\text { precursor }(\mathrm{Cu}-\mathrm{Zn})\end{array}$ \\
\hline Rv0934 & 374 & 40 & 23 & 1 & 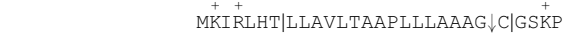 & PhoS precursor \\
\hline Rv1009 & 362 & 108,273 & 23 & 1 & 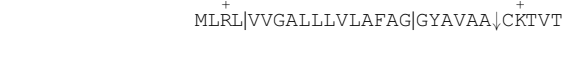 & $\begin{array}{l}\text { Rpf homologue (Mukamolova et } \\
\text { al., 1998) }\end{array}$ \\
\hline Rv1270c & 244 & 80 & 24 & 1 & $\stackrel{+}{\text { MKHPPCSV|VAAATAILAVVLAIGG } \downarrow C \mid S T E G}$ & $\begin{array}{l}\text { LprA, unknown function, } \\
\text { homologues reported (Bigi et al., } \\
\text { 1997; Oftung et al., 1997) }\end{array}$ \\
\hline Rv1274 & 185 & 46 & 24 & 2 & $\begin{array}{c}+++++ \\
\text { MRRKVRR|LTLAVSALVALF|PAVAG } \downarrow \text { CSDSSG }\end{array}$ & LprB, unknown function \\
\hline Rv1368 & 261 & 50 & 38 & 1 & 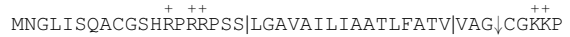 & LprF, unknown function \\
\hline
\end{tabular}

* The nomenclature from the M. tuberculosis H37Rv genome was used (Cole et al., 1998).

† Length of the translated gene in amino acids.

$\ddagger$ The fusion lengths of those proteins that were identified using PhoA fusion technology in this report are listed. The lengths given were counted from the predicted N-terminal start position of each protein.

\Length of the predicted signal peptide counting from the predicted N-terminal start position of each protein.

I This column indicates how many TM domains were predicted within each protein including the signal peptide using the Transmembrane Prediction Server. Only TM segments with a score of $>1000$ were considered significant. Proteins with more than one TM domain also had TM domains within the mature polypeptide.

$\|$ The $\mathrm{N}$-terminal region of each protein is shown in single-letter code. The positively charged residues, $\mathrm{K}$ and $\mathrm{R}$, are marked with a ' + ' sign above the sequence and the negatively charged residues, D and E, are marked with a '-' sign. Putative cleavage positions for the signal peptidase II are indicated by $\downarrow$. The two vertical bars (I) in each signal peptide mark the borders between the n-region and h-region, and the h-region and c-region, respectively.

were picked and restreaked to obtain single-colony isolates. The cycle of electroporating plasmids into M. smegmatis and screening for PhoA-positive colonies was repeated dozens of times until 300 separate blue colonies were collected.

We expected the screen to yield redundant representations of many different insert fragments because the cloned plasmids were propagated in E. coli before they were transferred to $M$. smegmatis. Redundant clones were identified by the restriction digestion patterns of the plasmids, using a panel of nine restriction enzymes (BamHI, EcoRV, FspI, HindIII, HpaI, MluI, PstI, PvuII and XbaI). We identified a putatively nonredundant set of 38 clones that formed the basis of all further analyses. In order to confirm that each of these non-redundant fusions expressed PhoA activity in M. smegmatis, plasmids from each clone were first electroporated back into $\mathrm{mc}^{2} 155$, and single-colony isolates of each were harvested and propagated separately. PhoA activity was evaluated by comparing the colour to the reference strain, $\mathrm{mc}^{2} 155 / \mathrm{pAW} 200$, which was streaked onto a sector of every plate.

The nucleotide sequences of the M. tuberculosis DNA inserts were obtained by Southwest Scientific Resources, Inc. (Albuquerque) and Lofstrand Labs Unlimited (Bethesda), by dye terminator chemistry with fluorescent detection performed on an Applied Biosystems model 373A (PE Biosystems). Plasmids purified from E. coli were used as templates for the PCR reactions. A combination of four primers was used to do the sequencing in from the vector, one proximal and one distal on each side of each M. tuberculosis insert. The primer sequences were: 5'-TGCAGTAATATCGCCCTGA3' (26 bp downstream from insert); 5'-CAGAGCGGCAGTCTGATC-3' (72 bp downstream from insert); 5'-GATATCGAATTCCTGCAG-3' (23 bp upstream from insert); 5'-CTCGAGGTCGACGGTATC-3' (49 bp upstream from the insert).
Sequence data analysis. Sequences of M. tuberculosis proteins and ORFs were obtained from the Sanger Centre at http://www.sanger.ac.uk/pub/tb/sequences, from the EMBL 56 and GenBank 109 releases, and from SWISS-PROT 36, NBRF-PIR 57, GenBank translated release 109 and Prosite 15. Sequences were analysed using the DNAStar programs EditSeq, Protean, MegAlign and GeneMan (DNASTAR Inc.).

The TMPred program, which is available from http://www.ch.embnet.org/software/TMPred/, was used for prediction of TM helices and the orientation of TM segments in membrane proteins. The SignalP program V1.1 and the beta release of $\mathrm{V} 2$, which is available from http:/www.cbs.dtu.dk/services/SignalP/, were used for SP motif and cleavage site predictions (Nielsen et al., 1997). The neural network (NN) method is trained on datasets from SWISS-PROT release 29 (V1.1) or release 35 (V2). The dataset trained on the Gram-positive sample is most relevant for prediction of mycobacterial SPs. The second version of the SignalP program also includes a new method for identification of SPs, the hidden Markov model (HMM). In addition to predicting the cleavage site it also divides the SP into its three constituent parts: the n-region, which is the $\mathrm{N}$-terminal part of the SP, generally characterized by having one or more positively charged amino acids, arginine $(\mathrm{R})$ or lysine $(\mathrm{K})$; the hydrophobic h-region which spans the cytoplasmic membrane; and the C-terminal part of the SP, the c-region, containing more polar amino acids and terminating with the conserved AXA motif which is the recognition site for signal peptidase I.

BLAST searches. To search for potential functions of the proteins, homologous proteins were found by the TBLASTn program in the databases 'All EMBL except EST' using PAM250 residue weight table $(2.5$ accepted mutations per residue). The computation was performed at the Swiss 
Institute of Bioinformatics (SIB) using the BLAST network service.

\section{RESULTS}

\section{Description of the phoA fusion experiments}

In summary, a total of 38 independent fusions were obtained. Upon sequencing of these clones, 34 different genes were identified. Based on the features of the encoded gene products, as described below, we classified the proteins as soluble secreted proteins (22), membrane lipoproteins (6) or integral membrane proteins (6).

Six genes had significant TM segments in the N-terminal region and appropriately placed membrane lipoprotein attachment sites (ProSite motif PS00013) (Table 1). Rv0432 (sodC) was identified by four, and Rv1009 by two independent fusions (Table 1). This finding may indicate that these genes have promoters that give strong expression when cloned into M. smegmatis. One of the fusions with sodC was only 11 amino acids long, constituting the n-region of the SP. Leaderless PhoA does not contain a discrete domain that targets it for export; however it has been shown that the addition of positively charged amino acids N-terminally may be sufficient for its insertion into the translocation machinery (Prinz et al., 1996). The short fusion with sodC supports the finding that the fusion of sequences with basic amino acids to leaderless PhoA may be sufficient for engaging it in the secretory pathway.

Six other genes encoded proteins with multiple predicted TM domains ( $>5$ ); accordingly, these were classified as membrane proteins (Table 2). PhoA fusions can be used to assign the correct orientation of membrane protein TM helices (Manoil \& Beckwith, 1986; Manoil et al., 1988) because the phosphatase is enzymically active when fused to loops that project outside the cytoplasmic membrane. This information was used to predict the orientation of the six proteins described in Table 2. However, using phoA fusions to predict the proper folding of membrane proteins may have pitfalls. It has been reported that fusions near the $\mathrm{N}$-terminal part of cytoplasmic loops may give false-positive signals, because they lack positively charged amino acids acting as topogenic signals (Prinz \& Beckwith, 1994). Examination of our fusions showed that none was close to the $\mathrm{N}$-terminus of the extramembranous loops. In addition, it is worth noting that the predicted orientations of the proteins described in Table 2 are based on only one PhoA fusion per molecule, and to assign the correct orientation and definition of all TM segments, several fusions at different points along the polypeptide chain are needed (Boyd et al., 1993).

We identified 22 genes encoding proteins with strong TM domains $\mathrm{N}$-terminally representing putative signal sequences (Table 3). Fourteen genes may encode novel secreted proteins. Seven coincided with previously described secreted proteins of the M. tuberculosis H37Rv genome (Rv0040c, Rv0129c, Rv1886c, Rv1980c, Rv2376c, Rv2878c and Rv3810). One gene coincided with the unannotated O1mtb1 (Chubb et al., 1998), which overlaps with Rv0192. In contrast to O1mtb1, Rv0192 does not have a putative SP sequence, and the codon usage of $\mathrm{O} 1 \mathrm{mtb} 1$ is more optimal. To provide a more reliable characterization of the mycobacterial SP, we extended Table 3 to contain 15 additional proteins, which have been reported in the literature to encode exported proteins of the M. tuberculosis complex. These proteins were included in this dataset based on published data on $\mathrm{N}$-terminal sequences or because they had been identified by PhoA or $\beta$-lactamase fusions by other authors. Table 3 thus contains a description of 37 probable secreted proteins. This dataset was used in the analysis that follows.

\section{Determination of signal peptidase I cleavage sites}

Possible cleavage sites for signal peptidase I were determined using the NN and the HMM methods. Comparison of the results showed that they predicted the same cleavage site in 21 of the 37 proteins in Table 3 whereas they diverged for the remaining 16 . In all but one ( $\mathrm{Rv} 3810)$ of these examples, the HMM method predicted longer SPs than the NN method. These results were compared to the experimentally determined cleavage sites $(n=16)$. The NN and HMM methods identified the correct cleavage sites in 10 and 12 of the 16 proteins respectively. The two methods were in agreement in 9 of these examples. In 3 examples (Rv2376c, $\mathrm{Rv} 2878 \mathrm{c}$ and $\mathrm{Rv} 3036 \mathrm{c}$ ) neither of the methods predicted the experimentally determined cleavage sites.

In some cases, the NN method predicts several alternative cleavage sites. The most notable example of this was Rv3803c (MPT51, fbpD). There are two very strong predictions of cleavage sites at position 27 and 34, of which the former yields a maximal C-score of 1.0 whereas the latter, which gave a C-score of 0.856, correctly predicted the experimentally determined cleavage site. In Rv3804c (Ag85A, FbpA), there are several possible AXA motifs and the NN method also predicts several possible cleavage sites with similar strengths, but the highest scoring one was not corroborated by the experimentally determined cleavage site. Because the new version of the SignalP program has been trained on a larger set of proteins, the old and new versions of SignalP predicted different optimal cleavage sites in Rv3804c. However, neither version identified the experimentally determined cleavage site for this protein.

\section{Prediction of TM domains in the secreted protein dataset}

Analysis of the predicted strength of the $\mathrm{N}$-terminal TM domains in the proteins listed in Tables 1 and 3 showed peak values of $1994 \pm 712(2 \mathrm{sD})(n=43)$ using the TM prediction program. Some of the secreted proteins also had significant TM domains within their mature parts. Each of the three antigen 85 complex proteins has a strongly hydrophobic region in the middle of the molecule, residues $\sim 160$ to $\sim 180$. Nonetheless, all of these proteins in their native states are completely 
Table 2. Putative membrane proteins identified by PhoA fusions

See also the footnotes to Table 1 for explanations of the columns.

\begin{tabular}{|lccccl|}
\hline Gene no. & $\begin{array}{c}\text { Total } \\
\text { length }\end{array}$ & $\begin{array}{c}\text { Fusion } \\
\text { length* }\end{array}$ & TM domains & $\begin{array}{c}\text { Predicted } \\
\text { orientation } \dagger\end{array}$ & \multicolumn{1}{c|}{ Alternative designations, comments } \\
\hline Rv1004c & 419 & 60 & 6 & N-in, C-in & Similarities with elastin \\
Rv1481 & 335 & 178 & 5 & N-in, C-out & Unknown \\
Rv2196 & 549 & 146 & 9 & N-out, C-in & Component of the ubiquinol-cytochrome $c$ reductase complex \\
Rv2563 & 388 & 207 & 5 & N-out, C-in & Unknown \\
Rv3157 & 553 & 71 & 12 & N-out, C-out & 'NuoM' subunit M of the NADH-CoQ reductase \\
Rv3252c & 416 & 51 & 6 & N-in, C-in & AlkB, non-haem iron monoxygenase \\
\hline
\end{tabular}

* The fusion lengths of those proteins that were identified using PhoA fusion technology in this report are listed in this column. The lengths given were counted from the predicted $\mathrm{N}$-terminal start position of each protein.

† Indicates whether the N-terminal and C-terminal ends of the proteins were predicted to be on the inside or outside of the cytoplasmic membrane.

soluble, demonstrating that soluble proteins may have at least one strong TM domain prediction. The antigen 85 complex has been found to consist of mycolyltransferases (Belisle et al., 1997) and the hydrophobic part might be within an active site that binds and transfers mycolic acids. Rv1274 also contains a TM domain within the mature part of the protein (residues 76-99). Whether this domain adopts a TM helix conformation must be determined experimentally.

\section{Characteristics of the mycobacterial SP}

Altogether 28 secreted proteins were selected from Table 3 to determine general characteristics of the M. tuberculosis SP. Proteins with known primary N-terminal amino acid sequences and/or proteins where the $\mathrm{NN}$ and the HMM methods predicted the same cleavage site were selected. The HMM method was used to determine the lengths of the n-, h- and c-regions of the SPs. The median SP length was 32 residues (range 21-49), the median n-region was 9 amino acids long (range 4-24), the median h-region was 16 amino acids (range 13-17) and the median c-region was 7 amino acids long (range 4-26). These figures are comparable to the lengths of SPs from Gram-positive bacteria (von Heijne \& Abrahmsen, 1989). The marked variability in the lengths of the cregions was due to three proteins with unusually long sequences (Rv2301, Rv2376c, Rv3033).

In terms of overall amino acid composition, the n-region of $M$. tuberculosis SPs is characterized by a high arginine content $(22 \%)$ and a relatively lower amount of lysine $(6.0 \%)$. The arginine-rich n-regions are most likely explained by the high $\mathrm{G}+\mathrm{C}$ content, which favours arginine because it is encoded by $\mathrm{G}+\mathrm{C}$-rich codons whereas lysine is encoded by G + C-poor codons. The overall amino acid composition of the h-region of the 28 selected signal sequences was $28 \%$ alanine, $18 \%$ leucine and $17 \%$ valine. In comparison Bacillus has only $10 \%$ alanine. Other bacterial SPs have generally more leucine $(25-35 \%)$. The overall composition of the c-region of the selected 28 signal sequences showed that the most abundant amino acids were: alanine, $33 \%$; glycine, $14 \%$; valine, $10 \%$; and proline, $9 \cdot 4 \%$.

Analysis of the preferred amino acids in the positions around the cleavage site showed that the mycobacterial SPs generally fulfil the $(-3,-1)$ rule, with alanine in 19 of 28 SPs in position -3 and alanine in 23 of 28 in the -1 position.

\section{The DP motif}

Aspartic acid (D) was the first $(+1$ position) amino acid of the mature sequence in 13 of $28(46 \%)$ entries in the dataset and proline $(\mathrm{P})$ was found in position +2 in 15 of $28(54 \%)$ of these secreted proteins. In 12 of $28(43 \%)$ of these, DP occurred simultaneously. The frequency of DP in any position of the 100 first proteins of $M$. tuberculosis was found to be less than $0.5 \%$. DP as a motif in the two first positions of mature secreted proteins has not been described in other bacterial species.

\section{Functional characterization of secreted proteins}

We performed BLAST searches on our selected set of proteins in order to make predictions about possible functions. Additional information was obtained for some of the proteins that was not available when the $M$. tuberculosis genomic sequence was published.

A relatively large fraction (56\%) of the lipoproteins in Table 1 and the secreted proteins listed in Table 3 are characterized as unknown. There were 19 previously characterized antigens, of which 10 have unknown function. Three proteins are potential virulence factors: Rv0590, Rv1566c and Rv2875. Rv1566 is a third homologue in $M$. tuberculosis to Listeria monocytogenes $\mathrm{p} 60$ invasion associated proteins (Kohler et al., 1990; Kuhn \& Goebel, 1989). Rv2875 (MPT70) has previously been reported to be homologous to osteoblast specific factor 2 (Ulstrup et al., 1995) and may be 
Table 3. Identification of signal peptides in previously and presently identified proteins

See also the footnotes to Table 1 for explanations of the columns.

\begin{tabular}{|c|c|c|c|c|c|c|c|}
\hline Gene no.* & $\begin{array}{l}\text { Total } \\
\text { length }\end{array}$ & $\begin{array}{l}\text { Fusion } \\
\text { length } \dagger\end{array}$ & $\begin{array}{c}\text { SP } \\
\text { length } \neq\end{array}$ & $\begin{array}{l}\text { Cleavage } \\
\text { prediction } \mathbb{S}\end{array}$ & $\begin{array}{c}\mathrm{TM} \\
\text { domains }\end{array}$ & Signal peptideg & $\begin{array}{l}\text { Alternative designations, } \\
\text { comments } \|\end{array}$ \\
\hline Rv0012AS & 247 & 87 & 32 & $\mathrm{HMM} / \mathrm{NN}$ & 2 & 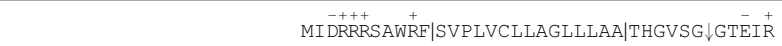 & Unknown function \\
\hline Rv0040c & 310 & 167 & 32 & $\mathrm{HMM} / \mathrm{NN}$ & 1 & 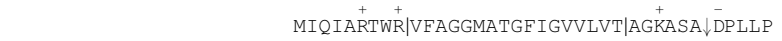 & MTC28, unknown function \\
\hline Rv0062 & 380 & 72 & $65 / 71$ & NN\&HMM & 1 & 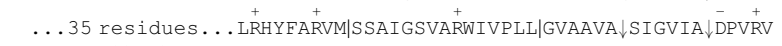 & CelA, possible cellulase \\
\hline Rv0116c & 251 & 178 & $28 / 47$ & NN\&HMM & 1 & 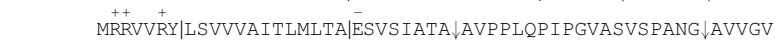 & Unknown function \\
\hline Rv0125 & 355 & - & 32 & $\mathrm{HMM} / \mathrm{NN} / \mathrm{NTS}$ & 1 & 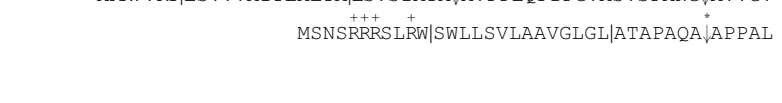 & $\begin{array}{l}\text { PepA, MTB32A, trypsin-like } \\
\text { serine protease (Skeiky et al., } \\
\text { 1999) }\end{array}$ \\
\hline Rv0129c & 340 & 65 & 46 & $\mathrm{HMM} / \mathrm{NN} / \mathrm{NTS}$ & 2 & 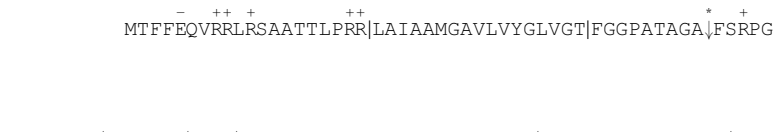 & $\begin{array}{l}\text { Ag } 85 \mathrm{C}, \mathrm{FbpC} \\
\text { mycolyltransferase (Nagai et } \\
\text { al., 1991; Wiker } \text { et al., 1990; } \\
\text { Chubb et al., 1998) }\end{array}$ \\
\hline Rv0283AS & 481 & 90 & $44 / 51$ & NN\&HMM & 1 & 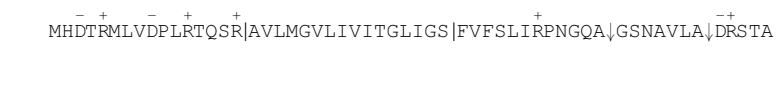 & $\begin{array}{l}\text { Unknown function, } \\
\text { ATP/GTP-binding site } \\
\text { PS00017 motif A }\end{array}$ \\
\hline Rv0431 & 164 & 75 & $34 / 57$ & NN\&HMM & 1 & 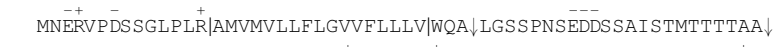 & Tuberculin-related peptide \\
\hline Rv0590 & 275 & - & 29 & $\mathrm{HMM} / \mathrm{NN}$ & 1 & 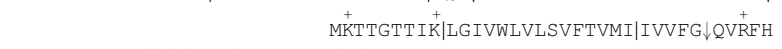 & Mce2B (Chubb et al., 1998) \\
\hline Rv0982 & 504 & 82 & 49 & $\mathrm{HMM} / \mathrm{NN}$ & 2 & 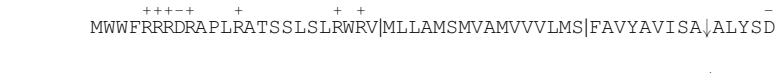 & $\begin{array}{l}\text { Putative two-component } \\
\text { sensor }\end{array}$ \\
\hline Rv1174c & 110 & - & 28 & $\mathrm{HMM} / \mathrm{NN} / \mathrm{NTS}$ & 1 & 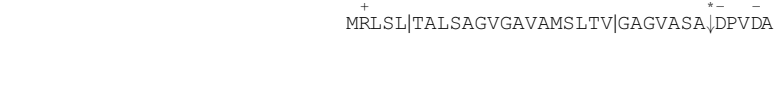 & $\begin{array}{l}\text { SA-5K, unknown function } \\
\text { (Coler } \text { et al., 1998; Freer } e t \\
\text { al., 1998) }\end{array}$ \\
\hline Rv1435c & 202 & - & 33 & $\mathrm{HMM} / \mathrm{NN}$ & 1 & MTLMAIVNRFNIK|VIAGAGLFAAAIAL|SPDAAA $\stackrel{+}{-} \stackrel{-}{\mathrm{DPLMT}}$ & $\begin{array}{l}\text { Unknown function (Chubb et } \\
\text { al., 1998) }\end{array}$ \\
\hline Rv1566c & 230 & 72 & 30 & $\mathrm{HMM} / \mathrm{NN}$ & 1 & 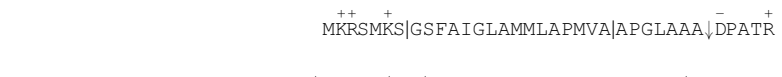 & $\begin{array}{l}\text { Homology with } M . \text { avium } \\
\text { invasin } 1 \text { (inv1) }\end{array}$ \\
\hline Rv1810 & 118 & 97 & 35 & $\mathrm{HMM} / \mathrm{NN}$ & 1 & 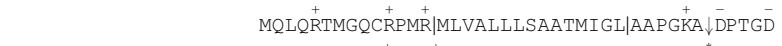 & Unknown function \\
\hline Rv1815 & 221 & - & 27 & $\mathrm{HMM} / \mathrm{NN} / \mathrm{NTS}$ & 2 & 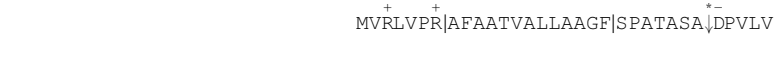 & $\begin{array}{l}\text { Protein F, unknown function } \\
\text { (Sonnenberg \& Belisle, 1997) }\end{array}$ \\
\hline Rv1860 & 325 & - & $39 / 60$ & NN/NTS\&HMM & 1 & 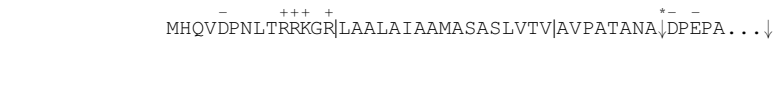 & $\begin{array}{l}\text { ModD, MPT32, Apa precursor } \\
\text { (Nagai } \text { et al., 1991; Romain } \\
\text { et al., 1993) }\end{array}$ \\
\hline Rv1886c & 325 & 59 & 40 & $\mathrm{HMM} / \mathrm{NN} / \mathrm{NTS}$ & 2 & 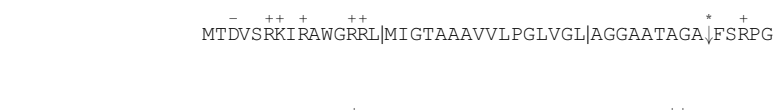 & $\begin{array}{l}\text { Ag 85B, FbpB, } \\
\text { mycolyltransferase (Nagai et } \\
\text { al., 1991; Wiker } \text { et al., 1986) }\end{array}$ \\
\hline Rv1910c & 197 & 54 & $22 / 33$ & NN\&HMM & 1 & 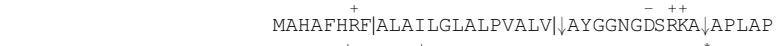 & Unknown function \\
\hline Rv1926c & 159 & - & 29 & $\mathrm{HMM} / \mathrm{NN} / \mathrm{NTS}$ & 1 & 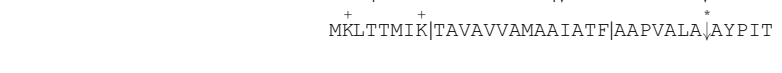 & $\begin{array}{l}\text { MPT63, unknown function } \\
\text { (Nagai et al., 1991) }\end{array}$ \\
\hline Rv1980c & 228 & 108 & 23 & $\mathrm{HMM} / \mathrm{NN} / \mathrm{NTS}$ & 1 & 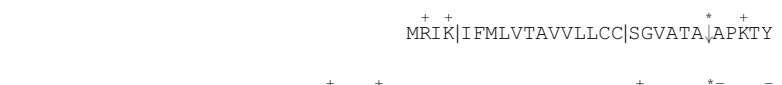 & $\begin{array}{l}\text { MPT64, unknown function } \\
\text { (Harboe } \text { et al., 1986) }\end{array}$ \\
\hline Rv1984c & 217 & - & $30 / 32$ & NN\&HMM/NTS & 2 & 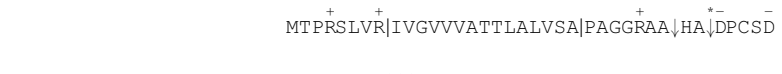 & $\begin{array}{l}\text { CFP21, putative cutinase } \\
\text { (Weldingh et al., 1998) }\end{array}$ \\
\hline Rv2253 & 167 & 99 & $27 / 28$ & NN\&HMM & 1 & 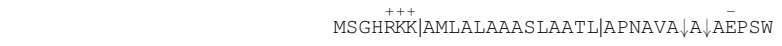 & Unknown function \\
\hline Rv2277c & 301 & 39 & $22 / 37$ & NN\&HMM & 1 & 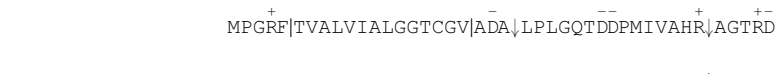 & $\begin{array}{l}\text { Putative } \\
\text { glycerolphosphodiesterase }\end{array}$ \\
\hline Rv2301AS & 230 & - & $32 / 43$ & NN\&HMM/NTS & 1 & 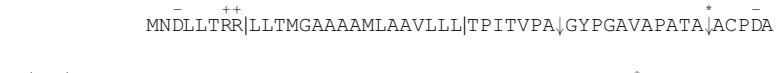 & $\begin{array}{l}\text { CFP25, putative cutinase } \\
\text { (Weldingh et al., 1998) }\end{array}$ \\
\hline Rv2376c & 168 & 49 & $21 / 48 / 53$ & $\begin{array}{l}\text { NN\&NTS } \\
\& H M M\end{array}$ & 1 & 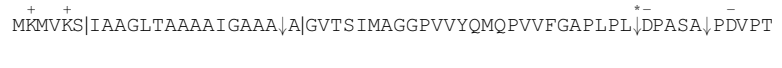 & $\begin{array}{l}\text { MTB12, unknown function } \\
\text { (Webb } \text { et al., 1998) }\end{array}$ \\
\hline Rv2875 & 193 & - & 30 & $\mathrm{HMM} / \mathrm{NN} / \mathrm{NTS}$ & 1 & 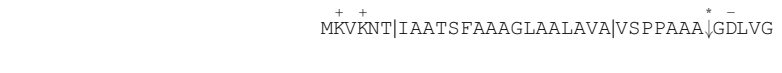 & $\begin{array}{l}\text { MPT70, OSF-2 homologue } \\
\text { (Harboe et al., 1986) }\end{array}$ \\
\hline Rv2878c & 173 & 130 & $37 / 38$ & NN/HMM\&NTS & 1 & 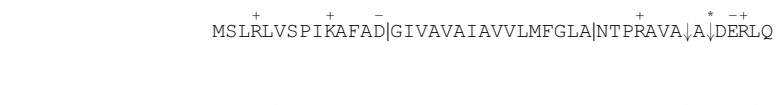 & $\begin{array}{l}\text { MPT53, thioredoxin-like } \\
\text { protein (Nagai } \text { et al., 1991; } \\
\text { Wiker } \text { et al., 1999a) }\end{array}$ \\
\hline Rv3033 & 182 & 83 & 40 & NN/HMM & 1 & MAHS IVRT|LLASGAATALIAIPTAC|SFS IGTSHSHSVSKA $\stackrel{+}{\text { EVARQ }^{-}}$ & Unknown function \\
\hline Rv3036c & 227 & - & $22 / 23 / 36$ & NTS\&NN\&HMM & 1 & $\stackrel{+}{M R Y L} \mid$ IATAVLVAVVLVGW|PAAG $\stackrel{*}{*}$ AP $\downarrow P S C A G L G G T V Q A \downarrow G Q I C H$ & $\begin{array}{r}\text { Protein B, MPT64 homologue } \\
\text { (Sonnenberg \& Belisle, 1997) }\end{array}$ \\
\hline Rv3310 & 299 & 248 & $36 / 46$ & NN\&HMM & 1 & 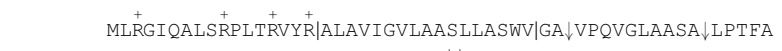 & Putative acid phosphatase \\
\hline Rv3492c & 160 & 46 & 21 & NN/HMM & 1 & $\begin{array}{c}++ \\
\text { MRRL|ISVAYALMVATIV|GLSA } \downarrow \text { AGGWF }\end{array}$ & $\begin{array}{l}\text { Unkown function, PS00213 } \\
\text { lipocalin signature }\end{array}$ \\
\hline $\operatorname{Rv} 3759 \mathrm{c}$ & 315 & - & 30 & NN/HMM & 1 & 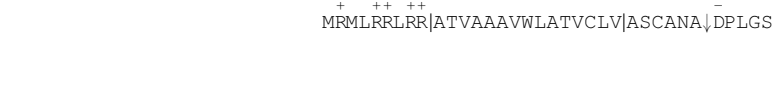 & $\begin{array}{l}\text { ProX, probable } \\
\text { osmoprotection protein } \\
\text { (Chubb et al., 1998) }\end{array}$ \\
\hline
\end{tabular}


Table 3 (cont.)

\begin{tabular}{|c|c|c|c|c|c|c|c|}
\hline Gene no.* & $\begin{array}{l}\text { Total } \\
\text { length }\end{array}$ & $\begin{array}{l}\text { Fusion } \\
\text { length } \dagger\end{array}$ & $\begin{array}{c}\text { SP } \\
\text { length } \neq\end{array}$ & $\begin{array}{l}\text { Cleavage } \\
\text { prediction } \mathbb{S}\end{array}$ & $\begin{array}{c}\mathrm{TM} \\
\text { domains }\end{array}$ & Signal peptide & $\begin{array}{l}\text { Alternative designations, } \\
\text { comments } \|\end{array}$ \\
\hline Rv3803c & 299 & - & $26 / 33$ & NN\&HMM/NTS & 1 & 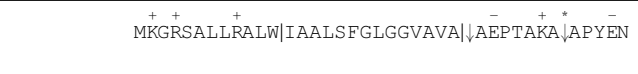 & $\begin{array}{l}\text { MPT } 51, \text { FbpD (Nagai et al., } \\
\text { 1991) }\end{array}$ \\
\hline Rv3804c & 338 & - & $34 / 43$ & NN\&HMM/NTS & 2 & 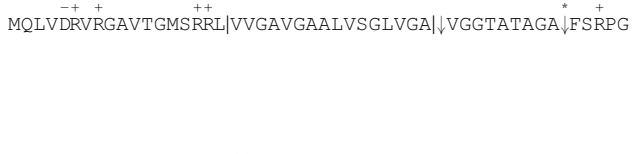 & $\begin{array}{l}\text { Ag85A, FbpA, } \\
\text { mycolyltransferase (De Bruyn } \\
\text { et al., 1987; Nagai et al., } \\
\text { 1991; Wiker et al., 1990; } \\
\text { Chubb et al., 1998) }\end{array}$ \\
\hline Rv3810 & 284 & 23 & $22 / 28$ & HMM\&NN & 1 & 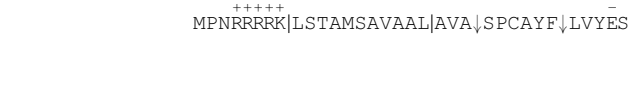 & $\begin{array}{l}\text { PIRG/Erp unknown function, } \\
\text { putative cell surface } \\
\text { precursor (Lim et al., 1995) }\end{array}$ \\
\hline $\begin{array}{l}\text { Not } \\
\text { assigned }\end{array}$ & 100 & 36 & 35 & NN/HMM & 1 & 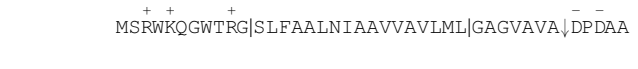 & $\begin{array}{l}\text { O1mtb1 (Chubb et al., 1998), } \\
\text { overlaps with Rv0192 }\end{array}$ \\
\hline $\begin{array}{l}\text { Not } \\
\text { assigned }\end{array}$ & - & - & 32 & NN/HMM & 1 & 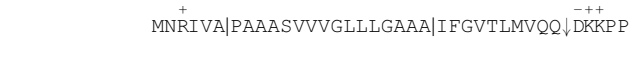 & pExp59 (Lim et al., 1995) \\
\hline
\end{tabular}

*AS, alternative start; indicates that a different start position than the annotated one was used.

† The fusion lengths of those proteins that were identified using PhoA fusion technology in this report are listed in this column. The lengths given were counted from the predicted $\mathrm{N}$-terminal start position of each protein.

$\ddagger$ Length of the predicted or experimentally verified signal peptide counting from the predicted $\mathrm{N}$-terminal start position of each protein. SIndicates how each of the cleavage positions for the signal peptidase I was determined: HMM, hidden Markov model; NN, neural network method; NTS, determined experimentally by N-terminal sequencing of the native purified protein. The most upstream prediction of the cleavage position is mentioned first. Different predictions are separated by ' $\&$ '. When separated by slashes (/), the methods predict the same cleavage position.

I Experimentally verified cleavage positions as determined by $\mathrm{N}$-terminal sequencing of the mature native protein are indicated by an asterisk (*).

|| The listed references contain information about $\mathrm{N}$-terminal amino acid sequences of native proteins except for two references (Chubb et al., 1998 and Lim et al., 1995) which were included due to identification by PhoA or $\beta$-lactamse fusions respectively.

relevant for development of bone tuberculosis. Four proteins are thought to be involved in cell wall biogenesis (the antigen 85 complex and MPT51, FbpA-D), and nine proteins are probable enzymes (superoxide dismutase, a cellulase, a protease, two cutinases, glycerolphophodiesterase, a thioredoxin-like protein, a protein possibly involved in hexuronate catabolism and a putative acid phophatase). Proteins secreted by Grampositive bacteria can serve as interbacterial signalling molecules, and one of the lipoprotein fusions found in this study (Rv1009) was recently identified as one of five genes in $M$. tuberculosis showing homology to the resuscitation promoting factor (Rpf) of Micrococcus luteus (Mukamolova et al., 1998).

Among the membrane proteins, Rv2196 was reported to have low similarity to cytochrome $b$ subunits. We also found that it shares strong homology to a component of the ubiquinol-cytochrome $c$ reductase complex of Streptomyces antibioticus, and Rv3252c was highly similar to alkane-1 monooxygenase of Pseudomonas aleovorans.

\section{DISCUSSION}

Characterization of exported proteins in pathogenic mycobacteria is important because it will provide a better understanding of the signals that direct proteins to the cell membrane, to the cell wall or to the surrounding milieu as soluble secreted products. Many of the exported proteins have key enzymic functions for building the mycobacterial cell wall, such as the antigen 85 complex, but the majority has not been functionally characterized yet. A complete list of exported proteins in mycobacteria is needed to obtain a more comprehensive picture of proteins involved in cell envelope biogenesis, immunogenicity and virulence. Potential candidates of the latter group are the proteins encoded in the four operons associated with mammalian cell entry (Arruda et al., 1993; Cole et al., 1998; Wiker et al., 1999b).

The PhoA fusion data presented in this report provide experimentally derived information about the identification and characterization of $M$. tuberculosis secreted proteins. Comparison of this empirical dataset with informatics-based predictions highlights both the potential and current limitations of the latter. For example, recognition of an authenic SP may depend on correct identification of the initiation codon. In some cases the annotated start codon may be located downstream of the actual start codon, as for Rv2301, which was annotated without the n-region of the SP. In other instances the correct start codon may be found further downstream. A new start site was identified in Rv1270c that is $39 \mathrm{bp}$ downstream of the previous one. Likewise, the pho $A$ fusion data also suggest that the correct start codons and RBSs of Rv0012 and Rv0283 are located downstream of those specified by the genome database. $\mathrm{Rv} 0062$ is an exception as it has a long N-terminal positively charged piece, but there is no obvious 
downstream RBS allowing an alternative interpretation. As a result, the putative SP would be unusally long.

The NN and HMM methods are not only designed to identify SPs, but also to predict the cleavage site for signal peptidase I. Our comparison with experimental data on known secreted mycobacterial proteins demonstrated good agreement with the general accuracy of prediction of cleavage sites by the $\mathrm{NN}$ and HMM methods (Nielsen \& Krogh, 1998), which are reported to give about $70 \%$ correct determinations. Our results suggest however that the HMM method gives better predictions than the NN method when applied to mycobacterial signal sequences. Relatively few mycobacterial proteins were included for training the $\mathrm{NN}$ method. Inclusion of proteins from the dataset presented here may improve the predictive accuracy of the $\mathrm{NN}$ method when applied to mycobacterial sequences.

For identification of secreted proteins, genomic data may be screened using algorithms for SP predictions (Gomez et al., 2000). However, due to inherent problems with the correct identification of initiation codons, the TM prediction server provides an attractive alternative for screening purposes to identify proteins with hydrophobic stretches in their N-terminal parts. Sequences that do not comply with the general characteristics of SPs may then be analysed more closely to reveal whether there are alternative start codons. Our results with the TM predictions in signal peptides show that they are strongly hydrophobic and give much higher scores $(>1000)$ than the cut-off value $(>500)$ suggested by the providers of the program. We find that TM predictions are sensitive and possibly ideal for screening purposes to identify novel secreted proteins in genomic datasets.

The M. tuberculosis genome is thought to contain a similar number of secreted proteins cleaved by signal peptidases I or II ( $~ 90$ in each group) (Cole et al., 1998). Assuming that this estimate is correct, Table 3 contains $\sim 40 \%$ of the total number of soluble secreted proteins of M. tuberculosis, and our fusions would have picked out $\sim 23 \%$ of the total number of secreted proteins processed by signal peptidase I. In comparison, $\sim 7 \%$ of the exported lipoprotein genes were obtained. Our fusion experiments thus more readily identified genes encoding putative soluble secreted proteins than genes encoding lipoproteins or membrane proteins. This bias could indicate that PhoA activity is more readily detected in fusion proteins that are released from the bacterial cell. Alternatively, the number of proteins processed by signal peptidase I may have been underestimated and could be considerably more numerous (estimated $\sim 200-300$ ).

Our analysis has revealed a novel motif (found in 12 of the presently recognized soluble secreted proteins), consisting of aspartic acid and proline (DP) in the first and second positions, respectively. The role of the DP motif is not known. It is possible that these amino acids are part of the recognition site for the signal peptidase I. However, because a range of different amino acids occur at these two positions in the other secreted proteins, considerable permissiveness must be allowed at the first and second positions of the mature sequence. Alternatively, the DP motif might function as a sorting signal that directs proteins to a particular compartment following translocation. A similar feature is well characterized in E. coli and Klebsiella oxytoca, where an aspartic acid in position +2 determines the inner membrane association of two lipoproteins (NlpA and pullulanase respectively) (Yamaguchi et al., 1988). Further experimental work is needed to determine if DP at the mature $\mathrm{N}$-terminus is a post-translocational sorting signal.

\section{ACKNOWLEDGEMENTS}

This work was supported by grants from Medinnova, Oslo, Norway, and AI 35060 and AI 44826 from the United States National Institutes of Health.

\section{REFERENCES}

Arruda, S., Bomfim, G., Knights, R., Huima-Byron, T. \& Riley, L. W. (1993). Cloning of an Mycobacterium tuberculosis DNA fragment associated with entry and survival inside cells. Science 261, 1454-1457.

Belisle, J. T., Vissa, V. D., Sievert, T., Takayama, K., Brennan, P. J. \& Besra, G. S. (1997). Role of the major antigen of Mycobacterium tuberculosis in cell wall biogenesis. Science 276, 1420-1422.

Bigi, F., Espitia, C., Alito, A., Zumarraga, M., Romano, M. I., Cravero, S. \& Cataldi, A. (1997). A novel $27 \mathrm{kDa}$ lipoprotein antigen from Mycobacterium bovis. Microbiology 143, 3599-3605.

Boyd, D., Traxler, B. \& Beckwith, J. (1993). Analysis of the topology of a membrane protein by using a minimum number of alkaline phosphatase fusions. J Bacteriol 175, 553-556.

Chubb, A. J., Woodman, Z. L., da Silva, T., Hoffmann, H. J., Scholle, R. R. \& Ehlers, M. R. (1998). Identification of Mycobacterium tuberculosis signal sequences that direct the export of a leaderless beta-lactamase gene product in Escherichia coli. Microbiology 144, 1619-1629.

Cole, S. T., Brosch, R., Parkhill, J. \& 22 other authors (1998). Deciphering the biology of Mycobacterium tuberculosis from the complete genome sequence. Nature 393, 537-544.

Coler, R. N., Skeiky, Y. A., Vedvick, T., Bement, T., Ovendale, P., Campos-Neto, A., Alderson, M. R. \& Reed, S. G. (1998). Molecular cloning and immunologic reactivity of a novel low molecular mass antigen of Mycobacterium tuberculosis. J Immunol 161, 2356-2364.

De Bruyn, J., Huygen, K., Bosmans, R., Fauville, M., Lippens, R., Van Vooren, J. P., Falmagne, P., Weckx, M., Wiker, H. G. \& Harboe, M. (1987). Purification, characterization and identification of a $32 \mathrm{kDa}$ protein antigen of Mycobacterium bovis BCG. Microb Pathog 2, 351-366.

Freer, G., Florio, W., Dalla, C. B., Bottai, D., Batoni, G., Maisetta, G., Senesi, S. \& Campa, M. (1998). Identification and molecular cloning of a novel secretion antigen from Mycobacterium tuberculosis and Mycobacterium bovis BCG. Res Microbiol 149, 265-275.

Gomez, M., Johnson, S. \& Gennaro, M. L. (2000). Identification of secreted proteins of Mycobacterium tuberculosis by a bioinformatic approach. Infect Immun 68, 2323-2327. 
Harboe, M., Nagai, S., Patarroyo, M. E., Torres, M. L., Ramirez, C. \& Cruz, N. (1986). Properties of proteins MPB64, MPB70, and MPB80 of Mycobacterium bovis BCG. Infect Immun 52, 293-302.

von Heijne, G. \& Abrahmsen, L. (1989). Species-specific variation in signal peptide design. Implications for protein secretion in foreign hosts. FEBS Lett 244, 439-446.

Jacobs, W. R. J., Kalpana, G. V., Cirillo, J. D., Pascopella, L., Snapper, S. B., Udani, R. A., Jones, W., Barletta, R. G. \& Bloom, B. R. (1991). Genetic systems for mycobacteria. Methods Enzymol 204, 537-555.

Kohler, S., Leimeister-Wachter, M., Chakraborty, T., Lottspeich, F. \& Goebel, W. (1990). The gene coding for protein p60 of Listeria monocytogenes and its use as a specific probe for Listeria monocytogenes. Infect Immun 58, 1943-1950.

Kuhn, M. \& Goebel, W. (1989). Identification of an extracellular protein of Listeria monocytogenes possibly involved in intracellular uptake by mammalian cells. Infect Immun 57, 55-61.

Lim, E. M., Rauzier, J., Timm, J., Torrea, G., Murray, A., Gicquel, B. \& Portnoi, D. (1995). Identification of Mycobacterium tuberculosis DNA sequences encoding exported proteins by using $p h o A$ gene fusions. J Bacteriol 177, 59-65.

Manoil, C. \& Beckwith, J. (1986). A genetic approach to analyzing membrane protein topology. Science 233, 1403-1408.

Manoil, C., Boyd, D. \& Beckwith, J. (1988). Molecular genetic analysis of membrane protein topology. Trends Genet 4, 223-226.

Mukamolova, G. V., Kaprelyants, A. S., Young, D. I., Young, M. \& Kell, D. B. (1998). A bacterial cytokine. Proc Natl Acad Sci USA 95, 8916-8921.

Nagai, S., Wiker, H. G., Harboe, M. \& Kinomoto, M. (1991). Isolation and partial characterization of major protein antigens in the culture fluid of Mycobacterium tuberculosis. Infect Immun 59, 372-382.

Nielsen, H. \& Krogh, A. (1998). Prediction of signal peptides and signal anchors by a hidden Markov model. In Proceedings of the Sixth International Conference on Intelligent Systems for Molecular Biology, pp. 122-130. Edited by J. Glasgow and others. ISBN 1-57735-053-7.

Nielsen, H., Engelbrecht, J., Brunak, S. \& von Heijne, G. (1997). A neural network method for identification of prokaryotic and eukaryotic signal peptides and prediction of their cleavage sites. Int J Neural Syst 8, 581-599.

Oftung, F., Wiker, H. G., Deggerdal, A. \& Mustafa, A. S. (1997). A novel mycobacterial antigen relevant to cellular immunity belongs to a family of secreted lipoproteins. Scand J Immunol 46, 445-451.

Prinz, W. A. \& Beckwith, J. (1994). Gene fusion analysis of membrane protein topology: a direct comparison of alkaline phosphatase and beta-lactamase fusions. J Bacteriol 176, 6410-6413.

Prinz, W. A., Spiess, C., Ehrmann, M., Schierle, C. \& Beckwith, J. (1996). Targeting of signal sequenceless proteins for export in Escherichia coli with altered protein translocase. EMBO J 15, 5209-5217.

Rauzier, J., Moniz, P. \& Gicquel-Sanzey, B. (1988). Complete nucleotide sequence of pAL5000, a plasmid from Mycobacterium fortuitum. Gene 71, 315-321.

Riley, M. (1993). Functions of the gene products of Escherichia coli. Microbiol Rev 57, 862-952.

Riley, M. (1998). Systems for categorizing functions of gene products. Curr Opin Struct Biol 8, 388-392.
Romain, F., Laqueyrerie, A., Militzer, P., Pescher, P., Chavarot, P., Lagranderie, M., Auregan, G., Gheorghiu, M. \& Marchal, G. (1993). Identification of a Mycobacterium bovis BCG 45/47kilodalton antigen complex, an immunodominant target for antibody response after immunization with living bacteria. Infect Immun 61, 742-750.

Sarmientos, P., Sylvester, J. E., Contente, S. \& Cashel, M. (1983). Differential stringent control of the tandem E. coli ribosomal RNA promoters from the rrnA operon expressed in vivo in multicopy plasmids. Cell 32, 1337-1346.

Skeiky, Y. A., Lodes, M. J., Guderian, J. A., Mohamath, R., Bement, T., Alderson, M. R. \& Reed, S. G. (1999). Cloning, expression, and immunological evaluation of two putative secreted serine protease antigens of Mycobacterium tuberculosis. Infect Immun 67, 3998-4007.

Sonnenberg, M. G. \& Belisle, J. T. (1997). Definition of Mycobacterium tuberculosis culture filtrate proteins by two-dimensional polyacrylamide gel electrophoresis, $\mathrm{N}$-terminal amino acid sequencing, and electrospray mass spectrometry. Infect Immun 65, 4515-4524.

van Soolingen, D., Hermans, P. W., de Haas, P. E., Soll, D. R. \& van Embden, J. D. (1991). Occurrence and stability of insertion sequences in Mycobacterium tuberculosis complex strains : evaluation of an insertion sequence-dependent DNA polymorphism as a tool in the epidemiology of tuberculosis. J Clin Microbiol 29, $2578-2586$.

Ulstrup, J. C., Jeansson, S., Wiker, H. G. \& Harboe, M. (1995). Relationship of secretion pattern and MPB70 homology with osteoblast-specific factor 2 to osteitis following Mycobacterium bovis BCG vaccination. Infect Immun 63, 672-675.

Webb, J. R., Vedvick, T. S., Alderson, M. R., Guderian, J. A., Jen, S. S., Ovendale, P. J., Johnson, S. M., Reed, S. G. \& Skeiky, Y. A. (1998). Molecular cloning, expression, and immunogenicity of MTB12, a novel low-molecular-weight antigen secreted by Mycobacterium tuberculosis. Infect Immun 66, 4208-4214.

Weldingh, K., Rosenkrands, I., Jacobsen, S., Rasmussen, P. B., Elhay, M. J. \& Andersen, P. (1998). Two-dimensional electrophoresis for analysis of Mycobacterium tuberculosis culture filtrate and purification and characterization of six novel proteins. Infect Immun 66, 3492-3500.

Wiker, H. G., Harboe, M., Nagai, S., Patarroyo, M. E., Ramirez, C. \& Cruz, N. (1986). MPB59, a widely cross-reacting protein of Mycobacterium bovis BCG. Int Arch Allergy Appl Immunol 81, 307-314.

Wiker, H. G., Sletten, K., Nagai, S. \& Harboe, M. (1990). Evidence for three separate genes encoding the proteins of the mycobacterial antigen 85 complex. Infect Immun 58, 272-274.

Wiker, H. G., Michell, S. L., Hewinson, R. G., Spierings, E., Nagai, S. \& Harboe, M. (1999a). Cloning, expression and significance of MPT53 for identification of secreted proteins of Mycobacterium tuberculosis. Microb Pathog 26, 207-219.

Wiker, H. G., Spierings, E., Kolkman, M. A. B., Ottenhoff, T. H. M. \& Harboe, M. (1999b). The mammalian cell entry operon (mce1) of Mycobacterium leprae and Mycobacterium tuberculosis. Microb Pathog 27, 173-177.

Yamaguchi, K., Yu, F. \& Inouye, M. (1988). A single amino acid determinant of the membrane localization of lipoproteins in $E$. coli. Cell 53, 423-432.

Received 29 November 1999; revised 3 April 2000; accepted 10 April 2000. 